\title{
De metodologia aos fundamentos e práticas de ensino de língua inglesa: a construção identitária profissional através do discurso.
}

\author{
Evellyn Juliane da Rocha Brandão \\ (FFP-UERJ/ PIBIC/CNPq)
}

\begin{abstract}
Resumo
Apoiando-me nos princípios da Prática Exploratória e no paradigma interpretativista de pesquisa, apresento neste trabalho minhas reflexões iniciais sobre o processo de formação identitária profissional dos professores de língua. Através da análise de algumas narrativas de professores em formação, busco entender como esse processo acontece através do discurso.
\end{abstract}

Palavras-chaves: identidade profissional, narrativa, Prática Exploratória, reflexão, entendimento.

\begin{abstract}
Using the principles of Exploratory Practice and the interpretativist paradigm, this paper presents my initial thoughts on the professional identity formation of language teachers. The analysis of some Pre-service teachers' narratives is used to understand how this process happens through discourse. Keywords: professional identity, narrative, Exploratory Practice, reflection, understanding.
\end{abstract}

\section{INTRODUÇÃO}

Apresento, neste trabalho, minhas considerações enquanto professora e pesquisadora em formação, acerca da construção social do professor de línguas que presencia a constante influência do mundo social dentro de sua sala de aula. A cada instante surgem novos olhares e interpretações sobre o que alguns autores chamam de modernidade tardia (Giddens, 1997; Giddens, Beck e Lash, 1997, apud Moita Lopes, 2003), pois, vive-se um momento de grande reflexividade. Em meio às mudanças da sociedade, novas identidades são construídas na interação face-a-face através da troca de experiências e sentidos sobre a vida contemporânea. Desta forma, o estudo das mesmas faz-se necessário, assim como o entendimento da construção identitária profissional. Acredito que esta construção aconteça no discurso e que o processo de formação docente deva ser entendido como permanente (Miller e Moraes Bezerra, 2004). Assim, fundamentada nos pressupostos do paradigma interpretativista (Moita Lopes, 1994) e nos princípios da Prática Exploratória (Miller, 2001; Allwright e Hanks, 
2009 inter alia), desenvolverei uma discussão sobre o papel do discurso para a formação dessa identidade profissional através da análise de narrativas de professores pré-serviço, a fim de compreender como esse processo de formação identitária acontece, revelando assim, minhas reflexões iniciais enquanto bolsista de iniciação científica e futura professora.

\section{DISCURSO E IDENTIDADE PROFISSIONAL}

Segundo Moita Lopes (2003:20), o que somos, nossa identidade social, é definida pelos discursos em que estamos envolvidos, i.e, se dá nos e pelos discursos. De acordo com Rollemberg (2003:251), “a construção da identidade [profissional] do professor é cercada de ideias e mitos desenvolvidos na sociedade, baseando-se principalmente nos aspectos negativos e positivos dessa caracterização". A autora destaca como aspecto negativo a falta de crédito que o professor vem recebendo em nosso país e a falta de estímulo das autoridades responsáveis pela educação. A imagem de que o professor é detentor do conhecimento e, através dele pode mudar a vida futura de seus alunos, são salientados como aspectos positivos. Segundo Rollemberg (ibid., p. 251) essas questões, apesar de influenciarem, não são determinantes e nem únicas nesse processo de formação identitária.

Ao agirmos socialmente, não o fazemos somente enquanto professores ou alunos, mas carregamos outros traços identitários como religião, raça, idade, classe social que também ajudam a nos definir (Rutherford 1990; Moita Lopes, 1998, apud. Rollemberg, 2003:251). Logo, o professor de línguas, assim como qualquer outro profissional, não é somente professor. Este é pai, mãe, filho, homem, mulher, tem suas crenças e visões sobre o mundo e, através da interação com o outro, se constrói professor e ser social.

Portanto, adoto neste trabalho uma visão socioconstrucionista do discurso e seguindo Moita Lopes, “entendo as identidades sociais como construções sociais e, portanto, discursivas, visto que aprendemos a ser quem somos nos encontros interacionais de todo dia" (Moita Lopes, 2003:27). Para ilustrar esse processo discursivo de formação identitária profissional, abordo a seguir a construção dessas identidades através das narrativas. 


\section{NARRATIVAS E CONSTRUÇÃO DA IDENTIDADE PROFISSIONAL}

O prazer que sentimos em contar e ouvir estórias desperta a curiosidade e nos ajuda a compreender a vida em sociedade. Ao narrar, nos envolvemos e envolvemos o outro em relações sociais, compartilhando nossas crenças e valores, como afirma Bastos (2005). Assim, cotidianamente, co-construímos conhecimento e nos (re)construímos como sujeitos.

Porém, Moraes Bezerra (2007) lembra que "as estórias que contamos não são contadas ingenuamente." Ao interagirmos com o outro não trocamos apenas experiências através do relato do que já aconteceu, mas construímos uma interpretação sobre essa experiência. As narrativas, mesmo que contadas mais de uma vez, terão sempre um novo significado, este co-construído com os participantes devido à multiplicidade de vozes na interação. Desta maneira, Bastos (2005:80) afirma que:

\footnotetext{
Podemos, desta forma, compreender o relato da narrativa mais como uma construção social do que como uma representação do que aconteceu, no sentido de que construímos as estórias que contamos em função da situação de comunicação (quando, onde e para quem contamos), de filtros afetivos e culturais, e do que estamos fazendo ao contar uma história.
}

Como um dos focos deste estudo recai sobre a construção social de professores Pré-serviço através do discurso, o estudo de narrativas faz-se necessário, visto que através delas é possível retomar como os participantes desta pesquisa, isto é, eu, professora-pesquisadora em formação e meus colegas, professores em formação, percebemos e vivemos o processo de formação identitária.

\section{A contribuição Laboviana}

Para Labov (1972; apud Bastos, 2005) a narrativa é "um método de recapitular experiências passadas”. Segundo ele, a sequencialidade e a reportabilidade são duas características cruciais para que haja uma narrativa. Além disso, Labov também afirma que toda narrativa é estruturada numa sequência temporal - possui orações narrativas com verbos no passado - tem um ponto e é contável (Ibid.). O ponto da narrativa é a razão pela qual ela existe, i.e., "o motivo pela qual ela é contada" (Bastos, 2004:119). Ela também precisa referir-se a algo extraordinário, tornando-a contável, atribuindo-lhe assim, reportabilidade. 
Mesmo sendo criticado pelos teóricos que o sucederam por ter se preocupado mais com a estrutura narrativa, as contribuições feitas por Labov acerca da estrutura das mesmas são de grande importância. Apresento abaixo os elementos básicos da estrutura narrativa proposta por Labov (1972), conforme Bastos (2005:75-76):

Resumo - aparece no início da narração sumarizando a narrativa.

$>$ Orientação - enunciados que ajudam a orientar os participantes da narrativa. Indentificam o tempo, o espaço, as pessoas envolvidas, a situação em que estão envolvidas na narrativa. Situam-se, principalmente, no início das narrativas, porém, podem ocorrer em outros momentos.

Ação complicadora - A estória em si. Formada a partir da sequência de orações narrativas construídas no pretérito perfeito, é o único elemento obrigatório em uma narrativa.

Avaliação - Para Bastos, o mais complexo e o mais fascinante elemento da estrutura narrativa, pois indica o seu ponto, carga emocional e dramática. Pode ocorrer de duas formas: ser externa - quando o fluxo da narrativa é suspenso pelo narrador a fim de relatar como este se sentiu durante determinado momento do evento narrado - ou interna/encaixada - quando o fluxo da narrativa é mantido, mas a avaliação é feita através de alguns recursos discursivos tais como diminuição ou aceleração do ritmo de fala, repetições, alongamentos de vogais, entre outros.

Coda - Esse tipo de fala traz narrador e ouvinte para o presente e marca o fim da narrativa.

Neste trabalho utilizarei alguns dos elementos acima que me ajudam a entender como o processo de construção identitária dos professores de língua ocorre, principalmente, a orientação e a avaliação. Assim, havendo apresentado as contribuições trazidas por Labov, destaco no item a seguir o estudo de Linde (1993) outra grande colaboradora para o estudo de narrativas. 


\section{Estórias de Vida}

Sem desconsiderar os constructos labovianos, Linde (1993) também contribui para os estudos de narrativas nos apresentando as estórias de vida, que conforme Bastos (2005:82) são:

[...] constantemente re-interpretadas e reformuladas. Por outro lado, são também essas estórias que dão ao indivíduo a possibilidade de compreender quem ele é. Como coloca Giddens (1991), a identidade pessoal é o eu compreendido pelo indivíduo em termos de sua biografia, sendo assim sua estabilidade dada por um sentido de continuidade biográfica que o indivíduo comunica aos outros.

Ao contarmos estórias de vida, portanto, mesmo apenas com informações que julgamos necessárias para que o outro nos conheça, não somente as utilizamos a fim de interagir com o outro, mas também para que façamos sentido sobre nós mesmos. Sendo assim, neste trabalho que busca entender como a identidade profissional é construída através do discurso, utilizo esse conceito a fim de resgatar nas estórias de vida de professores pré-serviço indícios desse processo formativo.

\section{PRÁTICA EXPLORATÓRIA E REFLEX̃̃O DOCENTE}

Aliada aos proponentes acerca das narrativas e do discurso, utilizo como posicionamento teórico a Prática Exploratória, uma proposta para entendimento da vida dentro e fora sala de aula. Os participantes envolvidos no processo de ensinoaprendizagem buscam, através do entendimento de questões (puzzles) que os aflijam, o desenvolvimento mútuo dos integrantes nas interações. Além disso, por surgirem através da co-construção de saberes e por conta do aprofundamento das questões ao longo do processo reflexivo, os puzzles ajudam a dar continuidade a este processo, visto que não são esperadas respostas definitivas para essas perguntas, mas sim novos olhares sobre o que intriga os envolvidos. Assim, dá-se a construção de uma atitude reflexiva, co-construída por professores e alunos. Tal atitude é norteada por alguns princípios, como sinalizam Miller et al.(2008:147) . São eles:

- Priorizar a qualidade de vida.

- Trabalhar para entender a vida em sala de aula ou em outros contextos profissionais.

- Envolver todos neste trabalho.

- Trabalhar para a união de todos.

- Trabalhar para o desenvolvimento mútuo. 
- Integrar este trabalho com as práticas da sala de aula ou com outras práticas profissionais.

- Fazer com que o trabalho para o entendimento e a integração sejam contínuos.

Como um dos objetivos do projeto de pesquisa do qual este trabalho se insere diz respeito ao entendimento do processo reflexivo na formação docente, e já que a minha pesquisa é realizada, na maioria das vezes, em encontros realizados em sala de aula, utilizo a Prática Exploratória seguindo a perspectiva apresentada por Miller et al. (2008:155):

\begin{abstract}
Ela [Prática Exploratória] se faz presente como uma proposta de desenvolvimento profissional que, buscando o entendimento dos porquês pré-existentes à qualidade de vida que se vive em sala de aula, não adota uma postura tecnicista voltada para o produto, para a mudança de técnicas de ensino, por exemplo. A Prática Exploratória enfatiza, em seu trabalho, o olhar para o processo, para as pessoas, para o humano, entendendo-os como elementos inseparáveis do profissional.
\end{abstract}

Desta forma, ao participar da pesquisa não o faço somente como pesquisadora e nem tão pouco só observo o contexto e me dedico à coleta de dados para a pesquisa. Ao contrário, me sinto parte dela, visto que compartilho de muitos puzzles e expectativas dos outros professores em formação envolvidos. Estes não são vistos aqui como meros colaboradores, mas participantes ativos na pesquisa, já que também trocam opiniões, indicam seus pontos de vista, deixando de serem os pesquisados, mas, juntos a mim, os co-construtores de significados acerca do nosso processo de formação inicial. Logo, assim como Miller et al.(2008:147), entendo que:

A Prática Exploratória opta pela busca de entendimentos mais profundos (ação para entender) ao invés da resolução precipitada de problemas (a ação para a mudança) e cria oportunidades para os praticantes exploratórios se 'apaixonarem' pelas questões, pela prática de questionar.

Assim, retomo nas narrativas de meus colegas, o que os intriga durante o nosso processo de formação identitária profissional, buscando envolver a todos nesse trabalho, e a olhar o processo de formação docente como permanente (Miller e Moraes Bezerra, 2007).

\title{
METODOLOGIA E CONTEXTO DA PESQUISA
}

O presente estudo está situado na tradição interpretativista (Moita Lopes, 1994) aliado aos princípios da Prática Exploratória (Miller, 2001; Moraes Bezerra, 2007; Allwright e Hanks, 2009, inter alia). À luz desses princípios, junto a meus colegas, 
praticantes exploratórios nesta pesquisa, busco entender o seguinte puzzle: Por que ser professor? Sendo assim, apresento a análise de algumas narrativas, transcritas dos dados que foram gerados em momentos de interação com eles.

Os dados foram gerados em uma universidade pública, situada na cidade de São Gonçalo, durante as aulas da disciplina Fundamentos e Práticas de Ensino de Língua Inglesa II. De acordo com o plano de periodização daquela universidade, a disciplina é frequentada, geralmente, por alunos que estejam no quinto período do curso de Letras (Português-Inglês). Nesta disciplina, trabalha-se a partir de uma perspectiva discursiva da língua, integrada a uma teorização vygotskiana. Nela, os alunos começam a planejar aulas de gramática e leitura em língua inglesa, sendo desafiados a pensar o ensino de línguas através de uma perspectiva crítico-reflexiva a fim de ajudá-los na construção de seu olhar acerca do ensino e aprendizagem de línguas.

É importante dizer que a maioria dos alunos no quinto período do curso de Letras já passou por disciplinas de educação, tais como Filosofia e Sociologia da educação, Didática e, para cursar a disciplina de Fundamentos e Práticas de Ensino de Língua Inglesa devem, necessariamente, ter cursado Metodologias de Ensino de Língua Inglesa. Portanto, os alunos que participaram desta pesquisa em outros momentos da graduação já estiveram em contato com teorias sobre ensino e aprendizagem e com discussões sobre a futura profissão.

Durante o segundo semestre do ano letivo de 2010, assisti às aulas da disciplina Fundamentos e Práticas de Língua Inglesa II, observando e participando das interações ocorridas em sala. Através da gravação de áudio das aulas devidamente autorizadas pela professora, Isadora, cuja prática docente é inspirada nos princípios da prática exploratória, e pelos alunos, resgato aqui as narrativas de quatro integrantes do grupo: Aline, Celli, Carlos e Ariana ${ }^{1}$.

\section{ANÁLISE DAS NARRATIVAS}

Como mencionado anteriormente, o foco desta análise está na interação de Ana, Celli, Carlos e Ariana. Nos fragmentos de suas narrativas, é possível notar o posicionamento destes alunos em relação à formação de professores e sobre o caminho por eles percorrido até o presente momento.

\footnotetext{
${ }^{1}$ Os nomes dos participantes das interações são fictícios.
} 
O primeiro excerto a ser analisado corresponde a uma conversa que tive com Aline e Celli a respeito de afirmações que permeiam nossa formação, porém, com o tempo, são desconstruídas por conta do processo de construção de nossa identidade e a partir do nosso crescimento durante o curso de licenciatura.

As demais análises foram realizadas a partir de uma apresentação de pôster feita por Aline e Carlos ao final da disciplina e conta com a participação de Ariana ao tecer um comentário durante a apresentação.

\section{Reflexão é crescimento}

Motivadas pela leitura de um dos textos em uma das aulas da disciplina que cursavam, Aline e Celli conversavam dentro da sala de aula sobre como a forma de observar a formação docente variava entre os alunos e, ao mesmo tempo, com o cursar das disciplinas durante a licenciatura. Como também discutia o texto com as duas naquele momento, participei deste momento reflexivo, perguntando à Aline se ela achava que as visões que possuíamos sobre o ensino eram motivadas por nossas crenças.

\begin{tabular}{|l|c|l|l|}
\hline Evellyn & 1 & E o que vocês acham sobre as crenças que vocês tinham se vocês tinham alguma coisa por exemplo \\
& 2 & ah: é impossível aprender Inglês em escola pública ou então é::.eu nunca quero ser professor nunca \\
& 3 & que meu filho vai estudar nesse lugar vocês ainda tem esse tipo de crença ou já tem no::v[as]? \\
\hline Aline & 4 & [Eu acredito] Eu acredito que isso aconteça mais devido a forma como a gente foi educado. Então você \\
& 5 & via lá o professor indo no quadro e dando todas aquelas regras de gramática e sempre ah::você tem \\
& 6 & que gravar: tem que decorar: e não dava assim uma outra forma pra você aprender,né? Não mostrava \\
& 8 & pra gente -não expunha aquela matéria de uma outra forma, talvez mais interessante, uma forma que \\
\hline Celli & 9 & [E muitas vezes] a gente acaba imaginando que não exista algum outro método, alguma outra forma e \\
& 10 & quando chegou em Fundamentos I, né?(olha para os demais participantes) Foi aquela coisa, sabe que \\
\hline Aline & 11 & abriu a mente da gente pelo menos pra mim,né? Ih..caraca tem outro jeito de você ensinar \\
\hline
\end{tabular}

Observamos que Aline e Celli refletem sobre sua formação inicial e começam a criticar a forma como os professores agiam enquanto elas ainda estavam na escola, como podemos verificar nos turnos de Aline (Linha4 a Linha7) ${ }^{2}$. Através da experiência

\footnotetext{
${ }^{2}$ A partir de agora, ao me referir às linhas utilizarei a letra $\mathrm{L}$
} 
que teve como aluna, ela reflete sobre aquele evento que vivenciou e, agora, como futura professora, não vê mais sentido no posicionamento adotado pelos professores da escola em que estudava. Embora Labov considere como único elemento obrigatório das narrativas a ação complicadora, i.e., uma sequência de orações narrativas, também vejo narrativa em trechos como o supracitado, pois, assim como Moraes Bezerra, acredito que o fato de as frases estarem no pretérito imperfeito ou no gerúndio pode ser uma forma de a narradora enfatizar - e avaliar - aquela forma de ensino que vivenciou, mas que agora analisa criticamente face às questões que estudava na disciplina Fundamentos e Práticas de Ensino de Língua Inglesa. Deste modo, em sua narrativa, Aline se posiciona de maneira contrária à prática daqueles profissionais, apesar de o entendimento sobre como ensinar aqui ser entendido como construído na interação com o outro.

Celli, por sua vez, entre L8 e L10, nos revela a importância de descobrir novas possibilidades, refletindo assim sobre o início de sua formação profissional. Ao citar o nome das disciplinas que já cursou, ela ajuda a situar o ouvinte para o momento em que o processo crítico-reflexivo começou, sendo esta uma das orientações presentes na narrativa. Assim, através dela, Celli revela que a forma de pensar como ela deveria ensinar foi modificada através da interação, já que a aluna também destaca a importância de disciplinas como a que cursava no momento - Fundamentos e Práticas de Ensino -, visto que foi a disciplina que ajudou a "abrir a mente de muita gente", assim como também destacam Miller e Moraes Bezerra (2007) quando apontam a importância de disciplinas que provoquem a reflexão durante a formação docente. Isso também pode ser observado ao final do turno de Celli (L.10), em que temos um exemplo de fala relatada, neste caso, indicando o momento de reflexão da aluna sobre as outras possiblidades de viver a experiência de ensinar e aprender.

\subsection{Tudo que sei é que nada sei}

Aline e Carlos apresentavam um pôster para a turma de Fundamentos e Práticas de Ensino. Neste pôster, cujo título era "Why the more we study the less we know?", através de imagens e questionamentos, eles buscavam entender esse puzzle (questionamento) que os intrigava. Para uma melhor organização na análise e na transcrição dos dados, decidi dividir o relato em três partes. 


\section{Why do the more we study the less we know?}

\begin{tabular}{|c|c|c|}
\hline Aline & 1 & O nosso questionamento surgiu até na verdade a gente tava no:: Semana Literária = \\
\hline Isadora & 2 & $=\mathrm{SEL}$ \\
\hline Aline & $\begin{array}{l}3 \\
4 \\
5 \\
6 \\
7 \\
8\end{array}$ & $\begin{array}{l}\text { Isso. Até quando estava você (Isadora) e a Roberta tavam falando e tal aí eu coloquei a mão na } \\
\text { cabeça aí eu falei nossa cara "Carlos!" A Mônica falando do Latim né:: e das coisas lá com o Lucas } \\
\text {...aí daqui a pouco Isadora com Roberta. Eu falei "Carlos. Pelo amo::r de Deus olha só!" } \uparrow \text { A gente } \\
\text { começou a pensar a gente:: assim "quanto mais a gente estuda menos a gente sabe porque é só o } \\
\text { começo." Me bateu um desespero ((risos de Aline e dos ouvintes)). Aí eu falei tipo: ah: né:: chegam } \\
\text { os nossos questionamentos "Why do the more we study the less we know?" }\end{array}$ \\
\hline
\end{tabular}

Por se tratar de uma apresentação de pôsteres em que um dos objetivos era a avaliação na disciplina, Aline inicia a narrativa (L1) já com uma orientação. Desta forma, situa a professora e os colegas da disciplina para o momento ao qual seu questionamento havia surgido. Para tanto, Aline utiliza um evento da área dos envolvidos que ocorreu semanas antes de sua apresentação na faculdade onde estuda. Isadora, professora da disciplina, toma o turno de Aline e inicia um pequeno reparo ao utilizar o nome do evento de forma abreviada. Ao fazer isso, torna-o mais compreensível, já que os presentes estavam mais acostumados com essa forma, o que pode ser constatado no turno subsequente (L3 - “Isso!"), em que Aline confirma o que foi dito por Isadora.

Aline, então, continua sua orientação referindo-se, agora, a uma apresentação de trabalho da professora em conjunto com outra docente da unidade acadêmica: "Até quando estava você (Isadora) e a Roberta tavam falando e tal". Porém, no mesmo turno (L3), a aluna começa a nos contar o que aconteceu. Temos aqui, o início da ação complicadora, que dura até L7.

Durante a orientação, Aline faz uma avaliação sobre a situação. Em "me bateu um desespero", notamos o que ela estava sentindo no momento em que percebeu que achava que não sabia nada. Além disso, a avaliação interna mostra a forma como aquele 
acontecimento deveria ser encarado pelos ouvintes também, algo assustador, desesperador.

No meio da L7, Aline parece encerrar o seu turno, apresentando como resolução o desenvolvimento do questionamento inicial: Aí eu falei tipo: ah: né:: chegam os nossos questionamentos "Why do the more we study the less we know?" Porém, a narrativa é retomada por Carlos ("Paralelo a isso"- L9), que dá a ideia de colocar uma fala de Sócrates, um dos maiores ícones da filosofia, como citação no pôster. Assim, ao escolher o que foi dito por uma pessoa de grande reconhecimento e utilizá-la aliando aos pensamentos que encontramos nas falas relatadas, percebemos que os dois recursos ajudam a dar mais credibilidade à narrativa dos dois alunos. Esta narrativa foi coconstruída por Carlos e por Aline, como podemos observar em L5-L6 “A gente começou a pensar" e L9 "Eu pensei a gente podia pegar uma frase" em que a ideia de construção conjunta fica evidente.

\section{Why?}

\begin{tabular}{|c|c|c|}
\hline ne & 18 & $\begin{array}{l}\text { E aí a gente tem o nosso primeiro questionamento né:: ((aponta para o pôster)) "Why are we in doubt } \\
\text { about it?" justamente por causa dessa questão:: porque quando a gente entra na faculdade -pelo } \\
\text { menos aconteceu comigo- eu achava tipo assim "nossa eu já sei muitas coisas. Terminei o Ensino } \\
\text { Médio e entrei numa faculdade pú:blica." Cheguei aqui e dá-Ihe na cabeça ((risos)) Não conseguia } \\
\text { nem fazer o primeiro trabalho: como:: fazer capa estruturar e tal. Comecei a ver que não era nada } \\
\text { daquilo e:: tudo que eu aprendi no Ensino Médio foi desconstruído. Aí eu comecei "Meu Deus do céu! } \\
\text { Eu aprendi tudo e não valeu a pena. Não aprendi nada. Tô começando tudo de novo". }\end{array}$ \\
\hline Carlos & 23 & $\begin{array}{l}\text { É::aí tem outro questionamento "Do you really think studying a lot really worth it?" porque ás vezes a: } \\
\text { chega numa hora que a gente pensa assim “ Nossa! É: é::no caso da professora elas tavam fala:ndo:: } \\
\text { falando do trabalho delas -da área delas aí por exemplo será que realmente vale a pena se } \\
\text { apronfundar numa área? Já pensou se eu me aprofundar numa área chego lá e descubro que não é } \\
\text { nada daquilo que eu queria. Como? E assim são questionamentos que a gente vai sentindo ao longo } \\
\text { da universidade. Que área seguir, se vai seguir, como vai seguir, como vai ser quando acabar isso } \\
\text { aqui ( ) se não acabar como a gente vai saber ((risos)) }\end{array}$ \\
\hline
\end{tabular}

Neste fragmento, destaco o ponto dessa narrativa: a dúvida desses alunos em tornarem-se professores. Essas dúvidas se refletem através dos puzzles que os alunos apontam nessa seção do trabalho. ("Why are we in doubt about it? Do you think studying a lot really worth it?"). 
Essas perguntas auxiliam na construção da identidade destes professores, pois é através da busca pelo entendimento destas questões que esses alunos passam a desenvolver uma atitude crítico-reflexiva. Assim, passam a observar o processo de formação pré-serviço na universidade com um olhar mais aguçado e intrigante.

A partir do primeiro puzzle, Aline inicia em L14 a ação complicadora de sua narrativa. Ela conta para os colegas, que terminou a escola e passou para uma faculdade pública. Nota-se que os eventos são ordenados em uma sequência temporal, no qual é possível perceber a ordem de acontecimento dos eventos. Porém, quando isso ocorre, Aline passa a acreditar que a experiência que possuía não valia nada. Para ela, seu processo de formação inicial é entendido como uma nova etapa, cheia de desafios, excluindo todo o conhecimento adquirido por ela anteriormente.

Carlos concorda com Aline. Notamos até aqui que os turnos de Aline são respeitados e co-sustentados por Carlos, pois, além de compartilhar das mesmas incertezas de Aline, age dessa forma a fim de dar continuidade ao trabalho que está sendo apresentado. O processo de reflexão dos dois é co-construído no momento da exposição do trabalho para a turma.

Apesar da fala de Carlos aqui não configurar narrativa, já que para Labov elas só existiriam se apresentassem uma sequência de duas ou mais orações com verbos no pretérito perfeito, utilizo aqui a fala de Carlos para entender aonde chegou o entendimento dos dois. Ao indagar se estudar muito vale mesmo a pena, Carlos utiliza a apresentação das professoras como um exemplo, revelando que se aprofundar em uma área valeria a pena. Por outro lado, na L21, ele reflete e revela que este seria um dos questionamentos que permeiam a formação "Já pensou se eu me aprofundar numa área chego lá e descubro que não é nada daquilo que eu queria. Como? E assim são questionamentos que a gente vai sentindo ao longo da universidade”. Por fim, Carlos nos mostra outras dúvidas sobre seu futuro como professor, mas conclui ao perceber que, somente terminando a licenciatura, será possível saber o que o espera.

\section{A teacher is a student forever}

Apesar de os fragmentos a seguir não serem considerados narrativas, os utilizo, assim como fiz com o relato de Carlos anteriormente, a fim de apresentar a que entendimentos esses alunos chegaram ao final de seu trabalho. Por surgirem a partir de fatos narrados pelos alunos e seus colegas, os trechos são de extrema importância para a 
compreensão do questionamento que norteia esta pesquisa, visto que ilustram o trabalho para entender as questões que permeiam a formação destes futuros professores.

\begin{tabular}{|l|l|l|l|}
\hline & 36 & E::: voltando, tudo que gente sabe é que não sabe nada. Então a gente tá sempre com essa \\
Carlos & 37 & sensação. Quando o aluno faz um questionamento pra gente. A gente fala" Nossa, a gente vai ter \\
& 38 & que buscar", então a gente volta, a: vai sempre buscar ou o que a gente pode tentando construir com \\
& 39 & os alunos -os alunos tem que saber mais que a gente que eles trazem conhecimentos que a gente \\
& 40 & vai agregar aos nossos e vice e versa pra construir juntos. \\
\hline Aline & 41 & E aí a gente coloca como uma pergunta pra vocês (aponta para os colegas da classe)" Do you think \\
& 42 & we have improved since the beggining of the university?" É:: vocês acham que vocês melhoraram, \\
\hline Carlos & 43 & que vocês né:: cresceram desde o início da faculdade até agora? \\
\hline Aline & 44 & A Aline já começa respon[de::ndo]. Ela acha que cresceu porque [ela \\
\hline Ariana & 46 & [É eu acho] \\
\hline Ariana & 47 & nas matérias de teoria literária entendeu::: que abre muito: pra você -até você chegar e deixar de \\
& 48 & lado= \\
\hline
\end{tabular}

Ao final da exposição oral, Carlos volta à citação de Sócrates por reconhecer que a busca é o caminho para o entendimento, destacando a importância da negociação e coconstrução de significados entre alunos e professores (L36-L40).

Aline, ao deixar uma pergunta para turma, mostra o quão relevante é esse momento na interação. Ao envolver todos os participantes na reflexão que, inicialmente, era só dela e de Carlos, Aline além de apontar o caminho que levou à reflexão dos dois, convida seus colegas para partilharem seus medos, incertezas, alegrias, prática semelhante a da professora daquela turma que desenvolveu todo o seu trabalho ao longo daquele semestre através da Prática Exploratória. Assim, é possível notar também que esses alunos aos poucos foram amadurecendo seus entendimentos e que aquela apresentação era o primeiro resultado desse processo de amadurecimento. Desta forma, para concluir seu modo de enxergar todos os questionamentos que permearam o seu trabalho, na linha 45 a aluna sobrepõe seu turno ao de Carlos, respondendo imediatamente à pergunta que ela lançou aos ouvintes. Ao fazê-lo, mostra que, apesar da insegurança inicial, passou a observar sua formação como professora de um modo 
diferente, onde os dilemas e conflitos ajudam no seu crescimento enquanto profissional em formação.

Ariana, colega de classe de Carlos e Aline, através da tomada do turno de Carlos, também responde a pergunta. Como é possível notar na L46, ela já não consegue mais ver o mundo da forma que via "há três anos atrás". Ariana destaca a importância de outra disciplina - Teoria literária -, que ampliou seus horizontes e, segundo ela, libertou alguns de seus preconceitos. Portanto, reconhece que a forma com que vê e interage com o mundo é reflexo dos discursos em que está envolvida, produzidos ou não em disciplinas, cujo foco seja a educação.

\section{CONSIDERAÇÕES FINAIS}

Uma vez que a pesquisa encontra-se em andamento, apresento algumas considerações inicias acerca deste estudo.

Neste trabalho analisei como alguns professores pré-serviço tornam-se professores, aprendendo a conviver com seus medos, incertezas, compartilhando suas opiniões e formando sua identidade profissional através das práticas discursivas em que estão envolvidos. Acredito, também, que os envolvidos nas narrativas analisadas, a partir de reflexões sobre eles mesmos e sobre a formação docente, conseguem perceber o quanto crescem e formam sua identidade profissional ao longo da graduação.

Durante essa primeira etapa da pesquisa tive livre acesso às aulas da disciplina já citada graças à colaboração da turma e da professora. Além disso, os dados aqui utilizados como forma de ilustrar o que vem sendo realizado por mim e pelos meus colegas é constantemente revisto e sempre retorna aos praticantes, que têm a oportunidade de dizer o que acharam sobre suas próprias falas. Assim, trabalhamos juntos a fim de co-construir entendimentos sobre o foi dito durante nossos encontros.

Assim como os meus colegas, também me encontro em meio a esses dilemas e questionamentos que me ajudam a construir minha identidade de professorapesquisadora em formação, considerando, portanto, que a pesquisa não pertence só a mim. Por isso, agradeço a todos os praticantes da nossa pesquisa, pela troca e crescimento durante as interações. 
[ ]sobreposição de turnos

( ) fala não compreendida

"palavra" fala relatada

$=$ engatamento de turno

(( )) comentários do analista

:: alongamento de vogal

T- refere-se ao turno de fala.

\section{REFERÊNCIAS}

Allwright, D. \& Hanks, J. (2009). The Developing Language Learner. Hampshire, United Kingdom: Palgrave Macmillan.

Bastos, L. C. (2005). Contando estórias em contextos espontâneos e institucionais - uma introdução ao estudo da narrativa. In: Calidoscópio (UNISINOS), São Leopoldo, RGS, v. 3 , n. 2, p. 74-87.

.(2004). Narrativa e vida cotidiana. In: Scripta (PUC-MG), Belo Horizonte, v.7, n.14, p. 118-127.

Giddens, A.(1991). Modernity and Self-Identity. Self Identity and Society in Late Modern Age. Standford: Standford University Press.

Giddens, A, Beck, U \& Lash, S. (1997). Modernização reflexiva. São Paulo: Editora da UNESP.

Labov,W.(1992). The transformation of experience in narrative syntax. In: Labov, W. Language in the inner city. Philadelphia, University of Philadelphia Press, p. 354-395.

Linde, C. (1993) Life stories, the creation of coherence. New York: Oxford University Press.

Loder, L. L. \& Jung, N. M. (Org.) (2008). Fala-em-interação social: introdução à Análise da Conversa Etnometodológica. 1. Ed. Campinas: Mercado de Letras.

Miller, I. K. (2001) Researching Teacher Consultancy Via Exploratory Practice: A Reflexive and Socio-Interactional Approach. Tese de Doutorado. Lancaster University. Reino Unido.

Miller, I. K. et al. (2008) Prática Exploratória: questões e desafios. In: Gil, G. \& VieraAbrahão, M.H. (Org.). Educação de Professores de Línguas: os desafios do formador. $1^{\mathrm{a}}$ ed. Campinas: Pontes Editores, p. 145-165.

Miller, I. K. \& Moraes Bezerra. I. C. R. (2007). Professor: um profissional em construção permanente. In. Revista Pesquisa em Discurso Pedagógico. Departamento de Letras, PUC- Rio, v.2. Disponível:http://www.maxwell.lambda.ele.pucrio.br/rev_discurso.php?strSecao=input 0 
Moita Lopes, L. P. da. (2003) Socioconstrucionismo: Discurso e Identidade. In : Moita Lopes, L. P.da.(org.). Discurso de Identidades: discurso como espaço de construção de gênero, sexualidade, raça, idade, profissão, na escola e na família. Campinas: Mercado de Letras.

.(1994). Pesquisa Interpretativista em Linguística Aplicada: a Linguagem como condição e Solução, DELTA, 10(2), pp.329-338.

.(1998). Discursos de identidade na sala de aulas de leitura de língua materna: a construção da diferença. In: SIGNORINI, I. (org.). Lingua(gem) $e$ identidade.Campinas: Mercado de Letras.

Moraes Bezerra, I. C. R. (2007). "Com quantos fios se tece uma reflexão” Narrativas e argumentações no tear da interação. Tese de Doutorado - Rio de Janeiro: Departamento de Letras, Pontifícia Universidade Católica do Rio de Janeiro.

Rollemberg, A. T. V. M. (2003). Historias de vida de duas professoras: narrativas como instrumento de construção da identidade profissional. In: Moita Lopes, L. P. da (Org.). Discursos de identidades: discurso com espaço de construção de gênero, sexualidade, raça, idade, profissão, na escola e na família. Campinas: Mercado de Letras, p. 249271.

Rutherford, J. (1990). Identity: community, culture, difference. Londres: Lawrence \& Wishart.

Tannen, D. \& Wallet, C.(2002). Enquadres interativos e esquemas de conhecimento: exemplos de um exame/ consulta médica. In: RIBEIRO, B. T.\& GARCEZ, P. M (orgs.) Sociolinguítica Interacional.São Paulo : Edições Loyola, p. 183-214.

\section{A AUTORA}

Evellyn Juliane da Rocha Brandão é aluna de graduação em Letras, com habilitação em Português-Inglês, na Universidade Estadual do Rio de Janeiro e bolsista de Iniciação Científica pelo CNPq no projeto de pesquisa "Formação Profissional Reflexiva do Professor de Línguas em Serviço e Pré-serviço", orientado pela Prof ${ }^{\mathrm{a}}$ Dr $^{\mathrm{a}}$ Isabel Cristina Rangel Moraes Bezerra, na Faculdade de Formação de Professores da UERJ.

E-mail: evebrandao@bol.com.br 
E.R.Brandão/Pesquisas em Discurso Pedagógico 2011.2 